\title{
Design, Mass Transfer Studies, and Optimization of an Air-Sparged Tubular Photocatalytic Reactor for the Degradation of Methylene Blue
}

\author{
Maria Lourdes P. Dalida and Patrick D. Ramoso
}

\begin{abstract}
An alternative process for the removal of organic pollutants in aqueous systems is photocatalysis. The challenges hindering its industrial use are electron-hole recombination and mass transfer limitations. In order to address these problems, the objective of this study is to introduce air by sparging, and design an air-sparged photocatalytic reactor using titanium dioxide immobilized on borosilicate glass. The performance of the reactor on the removal of the model pollutant, methylene blue (MB), was evaluated and compared against the reactor operated without sparging. The effect of mass transfer limitations on reactor performance was also investigated by regression using a Langmuir-type model equation. Reactor performance was optimized using Response Surface Methodology to determine the set of initial MB concentration, treatment time, initial $\mathrm{pH}$, and sparging rate that would result to the highest removal of methylene blue. The sparged photocatalytic reactor was able to degrade $57 \% \mathrm{MB}$ in 2 hours, an improvement of $40 \%$ compared to no sparging. Mass transfer limitation studies showed that the reactor operates near the reaction-limited regime, and that the extent of mass transfer limitation effects was reduced. The set of parameters that maximizes methylene blue removal were $2.0 \mathrm{ppm} \mathrm{MB,} 120$ minutes treatment time, $\mathrm{pH} 9.95$ and $2.0 \mathrm{~L} / \mathrm{min}$ sparging rate, with a predicted removal of $55.5 \%$. Validation experiments resulted to $57.2 \% \mathrm{MB}$ removal, and that the present reactor is comparable to similar reactors in literature, but with the advantage of using less expensive materials of construction and simpler immobilization technique.
\end{abstract}

Index Terms-Photocatalysis, response surface methodology, tubular photocatalytic reactor, wastewater treatment.

\section{INTRODUCTION}

The development of advanced wastewater treatment processes has been well studied over the years in light of the detrimental effects of water pollution, particularly organic compounds coming from industrial effluents. These treatment processes are classified under physical, chemical or biological [1], [2]. These treatment processes, however, have their own limitations. For example, adsorption processes have a problem with the disposal of spent adsorbent; chemical treatment processes may cause the formation of harmful byproducts; and biological processes are feasible only for contaminants that are not toxic to the microbes present in the system.

An alternative to these processes is photocatalysis, which

Manuscript received January 9, 2016; revised September 25, 2016. This work was supported in part by the University of the Philippines Engineering Research \& Development Foundation, Inc.

M. P. Dalida and P. D. Ramoso are with the Department of Chemical Engineering, University of the Philippines Diliman, Quezon City 1101, Philippines (e-mail: mpdalida@up.edu.ph,pdramoso@up.edu.ph). uses ultraviolet or visible light to initiate the degradation of organic pollutants using a photocatalyst, resulting to complete mineralization [2]-[5]. Photocatalysis offers an alternative because the degradation of pollutants is completethere are no unwanted byproducts; there is no transfer of pollutants from one phase to another; and its application is a wide range of pollutants.

Photocatalytic reactors may be classified either as suspended or immobilized systems. Suspended systems, although they have higher activity, have a limitation of requiring post-process separation since the photocatalyst is finely dispersed within the water being treated. This lowers the economic viability of these systems [3], [5]. Post-process separation is not required in immobilized systems, as the photocatalyst is anchored on a support. Immobilized systems, however, also have problems of their own, such as mass transfer limitations and electron-hole recombination, with the latter covering both immobilized and suspended systems. High mass transfer resistances result to a reactant concentration gradient between the bulk fluid and photocatalyst surface, resulting to lower rates of reaction [6]. Electron-hole recombination occurs as the excited electron in the conduction band returns and fills up the positive hole in the valence band. The series of reactions ceases, and photocatalytic activity decreases [3].

Mass transfer limitations are manifested by the dependence of the reaction rate $r$, or the apparent rate constant $k_{\text {app }}$, on the liquid velocity. Various studies have identified the existence of mass transfer limitations in many immobilized systems, such as tubular reactors [7], [8], annular reactors [9]-[11], rotating disc reactors [9], [12], and packed-bed reactors [7], [13], among others [14]. A commonly used model equation derived from first principles is a Langmuir-type equation based on volumetric flowrate $Q$ [15], [16]:

$$
r\left(\text { or } k_{a p p}\right)=\frac{a b Q}{1+a Q}
$$

These two challenges are to be addressed by introducing air into the system by sparging. Adding air bubbles lessens mass transfer limitation effects by promoting mixing of the liquid phase. Introducing air into the system adds an electron-scavenger into the system, with oxygen accepting excited electrons to form the superoxide ion. This leaves the holes available for mineralization to take place. The objective of this study is to design an air-sparged, tubular photocatalytic reactor using $\mathrm{TiO}_{2}$, study the effect of mass transfer limitations on its performance, and optimize reactor performance using Response Surface Methodology. 


\section{MATERIALS AND METHODS}

\section{A. Reactor Design}

The reactor consists of five tubes radially arranged with a total reactor volume of $600 \mathrm{~mL}$, and a 10W UVA lamp placed at the center of the reactor, as shown in Fig. 1 and Fig. 2. The tubes are made of borosilicate glass, and are fabricated with internal protrusions to promote turbulence and provide additional surface area for the catalyst [17]. The catalyst, Aeroxide ${ }^{\circledR} \mathrm{P} 25 \mathrm{TiO}_{2}$, was immobilized onto the tubes by spray coating with ethanol as carrier, and the tubes were dried and calcined in a muffle furnace. Air is sparged through nozzles directed at each tube such that the bubbles rise along the tubes as the water descends.

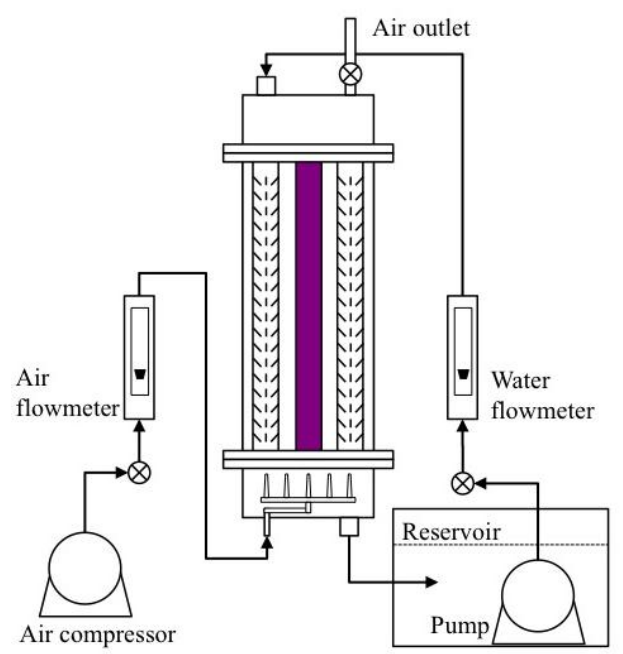

Fig. 1. Diagram of photocatalytic reactor.

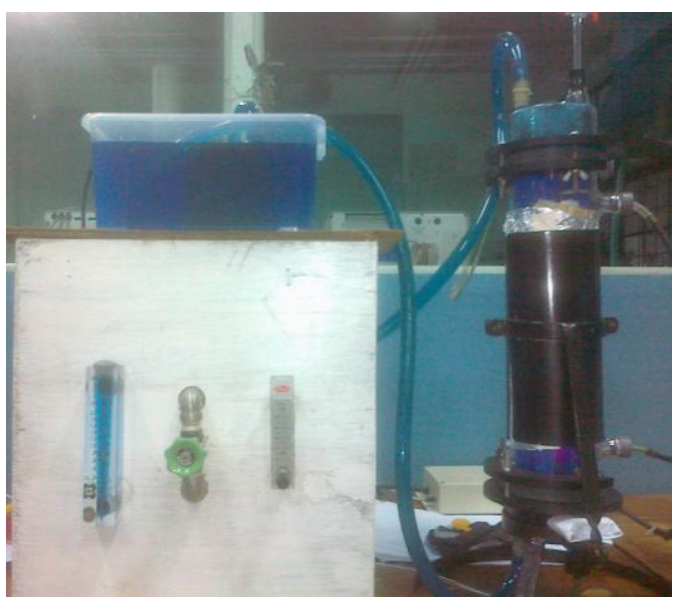

Fig. 2. Actual photocatalytic reactor set-up.

\section{B. Catalyst Characterization}

Samples of the immobilized photocatalyst were obtained by the destruction of one reactor tube after its calcination in order to characterize its surface. This was carried out by scanning electron microscopy (SEM) using a Hitachi S3400-N Scanning Electron Microscope. Images of tube surface were obtained at 300x and 1000x magnification [18].

\section{Reactor Performance Evaluation}

The performance of the reactor, measured as conversion or percent removal of methylene blue (MB), under sparged and non-sparged operation was compared at the following process parameters: $2.69 \mathrm{ppm}$ initial MB concentration, $\mathrm{pH} 7$, 2.8 liters per minute $(\mathrm{L} / \mathrm{min})$ water flowrate [17], and 2.0
$\mathrm{L} / \mathrm{min}$ air sparging rate, at 30, 60, 90 and 120 minutes. Adsorption (dark) and blank (no photocatalyst) runs were done to serve as control [18]. Methylene blue concentration was determined using a PerkinElmer Lambda 850 UV/VIS Spectrometer at a peak wavelength of $665 \mathrm{~nm}$.

\section{Mass Transfer Limitation Studies}

The effect of mass transfer limitations on the reaction rate was modeled for the sparged and non-sparged operation of the photocatalytic reactor using $2.69 \mathrm{ppm}$ initial methylene blue concentration and $\mathrm{pH} 7$, with a sparging rate of 2.0 $\mathrm{L} / \mathrm{min}$. To determine the effect of mass transfer limitations, the water flowrate was varied to 1.2, 1.6, 2.0, 2.4 and 2.8 $\mathrm{L} / \mathrm{min}$. The initial rate of reaction was determined based on a period of 20 minutes [18].

\section{E. Reactor Optimization}

Optimization using Response Surface Methodology was conducted to determine the set of parameters that results to the maximum conversion of methylene blue, using the Box-Behnken design of experiment. The levels of each factor are summarized in TABLE I. A total of 29 runs were performed, resulting to a quadratic model and the optimized set of parameters was tested in validation experiments [18].

\begin{tabular}{llll}
\multicolumn{4}{c}{ TABLE I: OPTIMIZATION STUDY: EXPERIMENTAL DETAILS } \\
\hline \hline Factor & Low value & Central value & High value \\
\hline Initial methylene blue & 2.0 & 20.0 & 38.0 \\
concentration (ppm) & & 90 & 120 \\
Treatment time (min) & 60 & 7 & 10 \\
Initial pH & 4 & 2.0 & 2.5 \\
Air flowrate (L/min) & 1.5 & & \\
\hline \hline
\end{tabular}

\section{RESULTS AND DISCUSSION}

\section{A. Catalyst Characterization}

SEM images of the reactor tube surface are presented in Fig. 3 and Fig. 4. It could be seen that the catalyst was immobilized throughout the surface of the glass; however, the coating is not uniform. The presence of wavelike patterns indicates a high surface area provided by the roughness of the immobilized surface; this morphology has been reported to increase photocatalytic activity [19]. In addition, the high magnification image in Fig. 4 illustrates the roughness of the surface, which may have resulted from the agglomeration of P25 $\mathrm{TiO}_{2}$ particles upon spray coating.

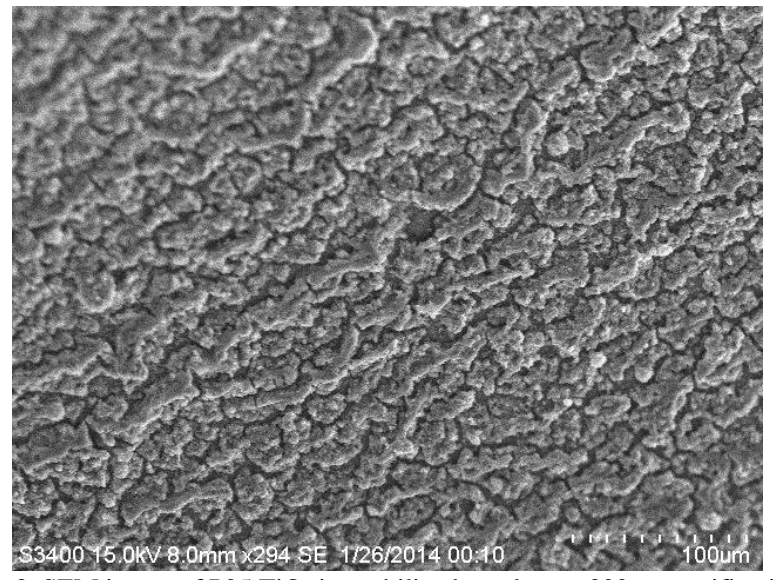

Fig. 3. SEM image of $\mathrm{P} 25 \mathrm{TiO}_{2}$ immobilized on glass at 300x magnification. 


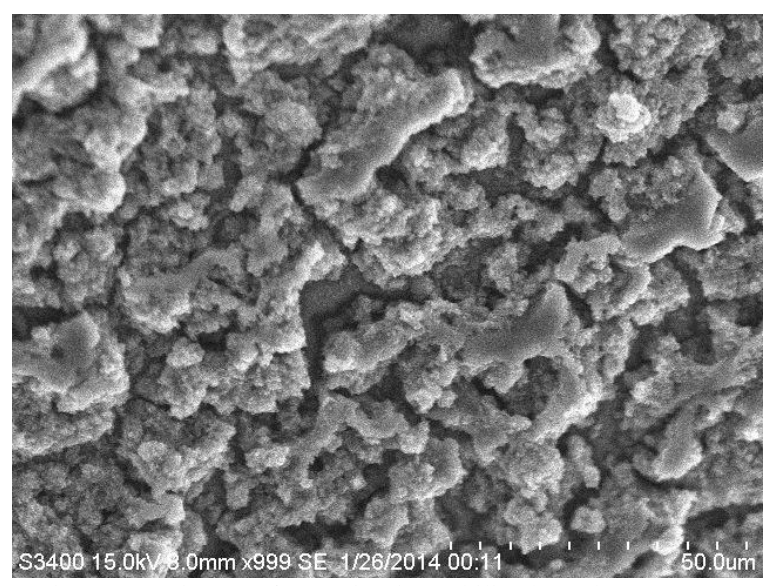

Fig. 4. SEM image of $\mathrm{P} 25 \mathrm{TiO}_{2}$ immobilized on glass at $1000 \mathrm{x}$ magnification.

It is also noted that catalyst entrainment cannot be assessed by surface characterization, as this would require the destruction of another reactor tube. Visual inspection of effluent samples, as well as reactor wash water, did not indicate any presence of entrained $\mathrm{TiO}_{2}$ particles. The small, if not negligible, extent of catalyst entrainment may be explained by the strong adhesion of the $\mathrm{P} 25 \mathrm{TiO}_{2}$ with the borosilicate glass, brought about by the use of ethanol as a carrier of the $\mathrm{TiO}_{2}$ suspension [18]. Due to the hydrophilic property of $\mathrm{P} 25 \mathrm{TiO}_{2}$ [20], the photocatalyst strongly adhered to the surface of the borosilicate glass, aided by the ethanol carrier.

\section{B. Reactor Performance Evaluation}

The performance of the reactor in the removal of methylene blue is shown in Fig. 5. It confirms that the dominant mechanism for the removal of methylene blue is photocatalysis, with $57 \% \mathrm{MB}$ removal after 120 minutes. The contribution of adsorption is less than $20 \%$. The negligible extent of $\mathrm{MB}$ adsorption on $\mathrm{TiO}_{2}$ is consistent with other studies [9], [21].

The control runs, which include adsorption on the reactor walls, tubings, reservoir walls, and pump internals, account for an average of $12 \% \mathrm{MB}$ removal. It is also noted that the control runs are already at steady state as early as 30 minutes, implying that the adsorption of methylene blue on internal surfaces is fast, but only contributes to a small extent.

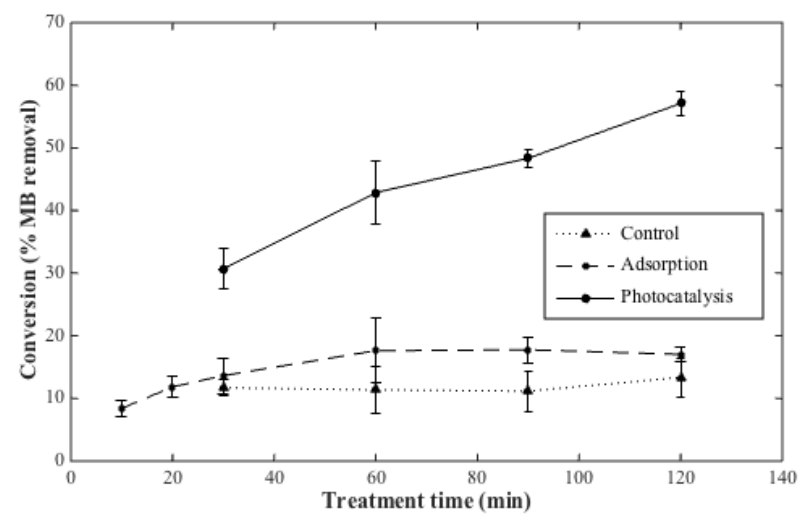

Fig. 5. Photocatalytic reactor performance.

The effect of sparging on reactor performance is illustrated in Fig. 6. The highest conversion of the sparged reactor is $57 \%$ at 120 minutes, higher compared to the $40 \%$ of the non-sparged reactor, or greater by a factor of $1.4(40 \%)$. This validates the use of air sparging to improve reactor performance. The sparging of air into the system resulted to higher dissolved oxygen concentrations in the system. Oxygen serves as an electron-scavenger, taking in the excited electrons, thereby lessening electron-hole recombination. In addition, the rising air bubbles also facilitate better mixing inside the reactor tubes, further increasing the removal of methylene blue [18].

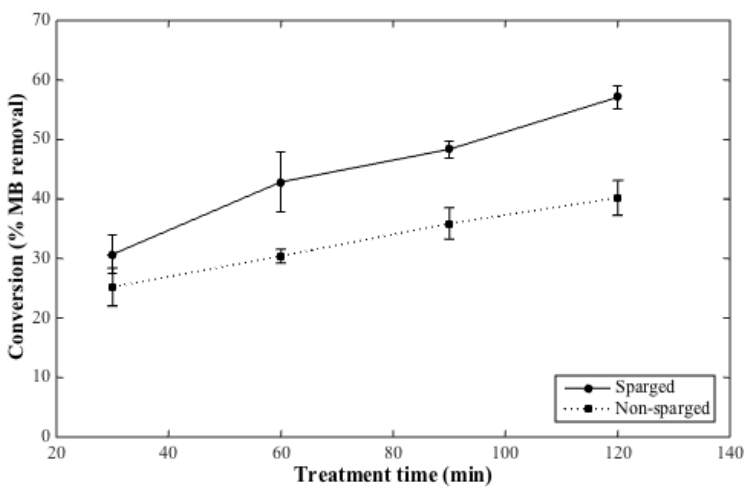

Fig. 6. Effect of sparging on reactor performance.

\section{Mass Transfer Limitation Studies}

The equations for the initial reaction rate, $r$, in $\mu \mathrm{mol} / \mathrm{L}-\mathrm{min}$, in terms of water flowrate, $Q$, for sparged and non-sparged operations are shown in equations (2) and (3), respectively. The initial reaction rates are plotted in Fig. 7 below.

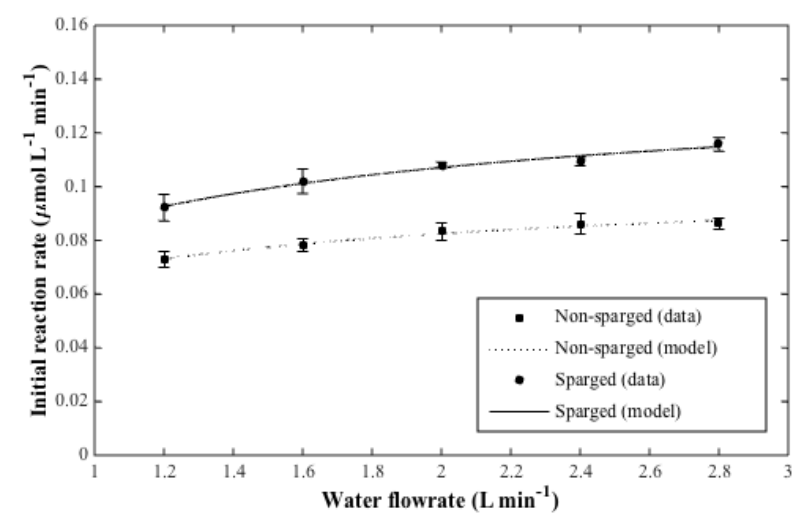

Fig. 7. Effect of mass transfer limitations on reactor performance.

$$
\begin{gathered}
r=\frac{0.1399 Q}{0.6120+Q} \\
r=\frac{0.1024 Q}{0.4822+Q}
\end{gathered}
$$

The experimental results gave rise to a good fit for both non-sparged and sparged reactor operation models, having $R^{2}$ values of 0.9825 and 0.9793 , respectively. This confirms a good fit to the Langmuir-type equation relating initial reaction rate with water flowrate. The small slopes seen in both models suggest that the studied range of flowrates is near the reaction-limited regime, and far from the diffusion-limited regime, which is characterized by relatively steep slopes. This observation becomes more obvious when the models are extrapolated to higher and lower flowrates, as seen in Fig. 8. With this, it could be concluded that at the 
range of flowrates studied, particularly at the higher end of the range, the problem of mass transfer limitations has been addressed by the present reactor [18].

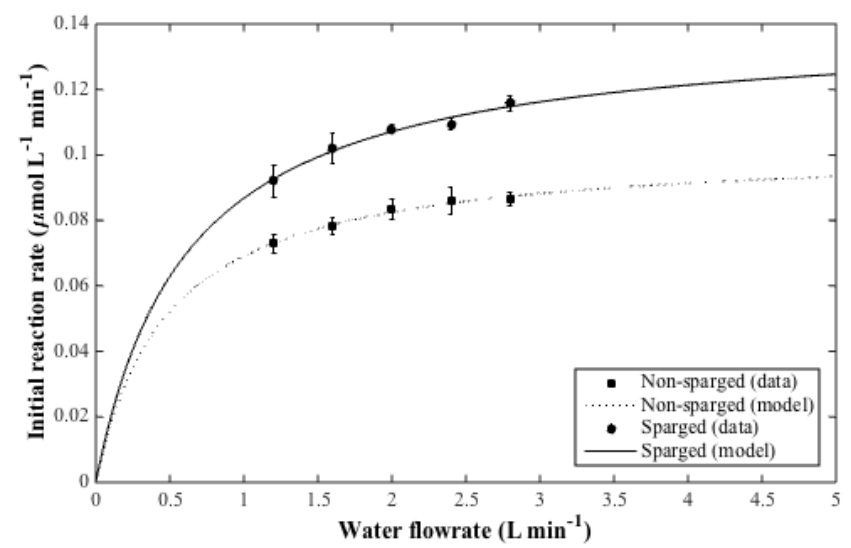

Fig. 8. Effect of mass transfer limitations on reactor performance (model extrapolated).

It is also noted from the plots above that the air-sparged reactor operates at higher rates of reaction than the non-sparged reactor, with maximum initial rates of 0.1157 and $0.0864 \mu \mathrm{mol} \mathrm{L} \mathrm{min}^{-1}$, respectively. This further supports the result that air sparging improved the performance of the reactor, as explained in the previous subsection.

\section{Reactor Optimization}

The optimization experiments resulted to a reduced quadratic response surface model, shown in equation (4) below. It is noted that methylene blue removal was found to be independent of air sparging rate, which may be due to the saturation of dissolved oxygen at the minimum sparging rate of $1.5 \mathrm{~L} / \mathrm{min}$. This leaves initial concentration (ppm), treatment time (min) and initial $\mathrm{pH}$ as the variables in equation (4). The response surface is plotted in Fig. 9 and Fig. 10.

$$
\begin{gathered}
\text { Conversion }=-7.602-2.261 \cdot(\text { initial conc. }) \\
+0.136 \cdot(\text { initial conc. })+10.266 \cdot(\text { initial } \mathrm{pH}) \\
+0.0366 \cdot(\text { initial conc. })^{2}-0.516 \cdot(\text { initial } \mathrm{pH})^{2}
\end{gathered}
$$

It is observed from the figures above that as the initial MB concentration increases, MB removal decreases. This is due to the lower UV penetration to the $\mathrm{TiO}_{2}$ surface from a greater amount of adsorbed methylene blue on the catalyst surface. Methylene blue removal increases with treatment time because of the greater contact between fluid and photocatalyst. Finally, MB removal increases with $\mathrm{pH}$ because of the greater affinity between methylene blue, a cationic dye, and the $\mathrm{TiO}_{2}$ surface, which is negatively charged at $\mathrm{pH}$ greater than the $\mathrm{pH}$ at the point of zero charge $\left(\mathrm{pH}_{\mathrm{pzc}}\right)$, which is 6.8 for $\mathrm{TiO}_{2}$ [22], as illustrated by the following equilibria [23]:

$$
\begin{array}{cc}
\mathrm{pH}>\mathrm{pH}_{\mathrm{pzc}}: & \mathrm{TiOH}+\mathrm{OH}^{-} \Leftrightarrow \mathrm{TiO}^{-}+\mathrm{H}_{2} \mathrm{O} \\
\mathrm{pH}<\mathrm{pH}_{\mathrm{pzc}}: & \mathrm{TiOH}+\mathrm{H}^{+} \Leftrightarrow \mathrm{TiOH}_{2}^{+}
\end{array}
$$

Based from the obtained response surface model, a set of parameters was obtained by Design Expert ${ }^{\circledR}$ software that would give the highest removal of methylene blue. These were $2.0 \mathrm{ppm}$ initial $\mathrm{MB}$ concentration, 120 minutes treatment time, and an initial $\mathrm{pH}$ of 9.95 , and the air flowrate set to the central value of $2.0 \mathrm{~L} / \mathrm{min}$, with a predicted $\mathrm{MB}$ removal of $55.5 \%$.

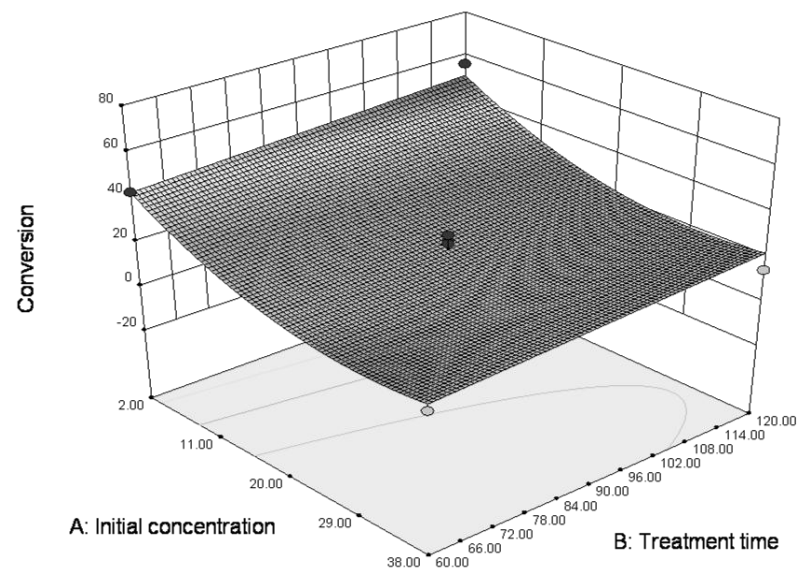

Fig. 9. Methylene blue removal at initial $\mathrm{pH} 7$ and $2.0 \mathrm{~L} / \mathrm{min}$ sparging rate.

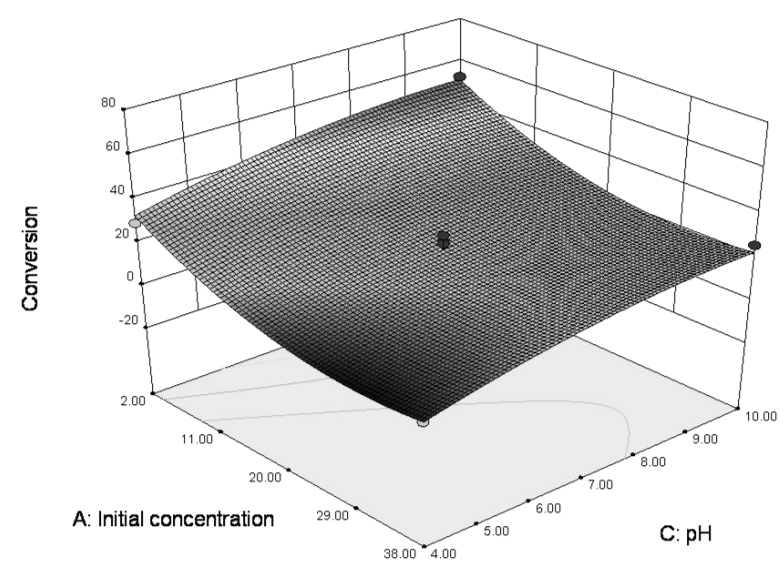

Fig. 10. Methylene blue removal at 90 minutes treatment time and $2.0 \mathrm{~L} / \mathrm{min}$ sparging rate.

Validation experiments resulted to an average MB removal of $57.2 \%$. The reactor performs better than other reactors in related studies [21], [24], [25] and may be considered at par with some reactors [9], but with the advantage of using a simpler immobilization method (spray coating) and the use of less expensive materials of construction (borosilicate glass) [18].

\section{CONCLUSION}

An air-sparged tubular photocatalytic reactor with immobilized $\mathrm{P} 25 \mathrm{TiO}_{2}$ photocatalyst was designed to lessen electron-hole recombination and promote mixing. Surface characterization showed a good immobilization of $\mathrm{TiO}_{2}$ by spray coating and calcination; no observable catalyst entrainment was found by visual inspection of reactor effluents.

The dominant mechanism for methylene blue removal is photocatalysis, with negligible contribution of adsorption on $\mathrm{TiO}_{2}$ and other internal surfaces of the reactor. Air sparging improved the performance of the tubular photocatalytic reactor by a factor of $40 \%$. Mass transfer limitation studies indicate a good fit to a Langmuir-type equation to relate the 
initial reaction rate with liquid volumetric flowrate. It also confirms that the present reactor operates closer to the reaction-limited regime, and that the extent of mass transfer limitation effects has been lessened in this reactor.

The set of parameters resulting to the maximum methylene blue removal consists of $2.0 \mathrm{ppm}$ initial $\mathrm{MB}$ concentration, 120 minutes treatment time, initial $\mathrm{pH}$ of 9.95 and $2.0 \mathrm{~L} / \mathrm{min}$ sparging rate, with a predicted removal of $55.5 \%$; validation runs resulted to an average removal of $57.2 \%$. The reactor performance is comparable to that of other similar reactors in literature. However, the reactor of the present study offers an advantage of using a simpler immobilization technique and a less expensive material of construction.

\section{ACKNOWLEDGMENT}

The authors would like to thank the Department of Chemical Engineering, University of the Philippines Diliman for the use of its laboratory and analytical equipment.

\section{REFERENCES}

[1] M. R. Hoffmann, S. T. Martin, W. Choi, and D. W. Bahnemann, "Environmental Applications of Semiconductor Photocatalysis," Chem Rev., vol. 95, pp. 69-96, 1995.

[2] R. Vinu and G. Madras, "Photocatalytic degradation of water pollutants using Nano-TiO2," in Energy Efficiency and Renewable Energy through Nanotechnology, L. Zang, Ed. London: Springer London, 2011, pp. 625-677.

[3] H. de Lasa, B. Serrano, and M. Salaices, Photocatalytic Reaction Engineering, New York: Springer Science+Business Media, LLC, 2005, ch. 1-2.

[4] A. Mills and S. Le Hunte, "An overview of semiconductor photocatalysis," J. Photochem. Photobiol. A Chem., vol. 108, pp. 1-35, 1997.

[5] D. F. Ollis, E. Pelizzetti, and N. Serpone, "Photocatalyzed destruction of water contaminants," Environ. Sci. Technol., vol. 25, no. 9, pp. 1522-1529, 1991.

[6] D. Chen, F. Li, and A. K. Ray, "External and internal mass transfer effect on photocatalytic degradation," Catal. Today, vol. 66, no. 2-4, pp. 475-485, Mar. 2001.

[7] M. F. J. Dijkstra, E. C. B. Koerts, A. A. C. M. Beenackers, and J. A. Wesselingh, "Performance of immobilized photocatalytic reactors in continuous mode," AIChE J., vol. 49, no. 3, pp. 734-744, 2003.

[8] M. F. J. Dijkstra, H. Buwalda, A. W. F. De Jong, A. Michorius, J. G. M. Winkelman, and A. A. C. M. Beenackers, "Experimental comparison of three reactor designs for photocatalytic water purification," Chem. Eng. Sci., vol. 56, pp. 547-555, 2001.

[9] I. Boiarkina, S. Norris, and D. Alec, "The case for the photocatalytic spinning disc reactor as a process intensification technology: Comparison to an annular reactor for the degradation of methylene blue," Chem. Eng. J., vol. 225, pp. 752-765, 2013.

[10] D. Chen, F. Li, and A. K. Ray, "Effect of mass transfer and catalyst layer thickness on photocatalytic reaction," AIChE J., vol. 46, no. 5, pp. 1034-1045, May 2000.

[11] M. F. J. Dijkstra, H. J. Panneman, J. G. M. Winkelman, J. J. Kelly, and A. A. C. M. Beenackers, "Modeling the photocatalytic degradation of formic acid in a reactor with immobilized catalyst," Chem. Eng. Sci., vol. 57, no. 22-23, pp. 4895-4907, Nov. 2002.

[12] D. Dionysiou, M. T. Suidan, I. Baudin, and J.-M. Laine, "Oxidation of organic contaminants in a rotating disk photocatalytic reactor: Reaction kinetics in the liquid phase and the role of mass transfer based on the dimensionless Damköhler number," Appl. Catal. B Environ., vol. 38, pp. 1-16, 2002.

[13] Y. Hama, M. Itamochi, T. Horikawa, M. Katoh, and T. Tomida, "Performance of a bench-scale annular-type packed-bed photocatalytic reactor for decomposition of indigo carmine dissolved in water," $J$. Chem. Eng. Japan, vol. 42, no. 7, pp. 502-507, 2009.

[14] B. Serrano and H. de Lasa, "Photocatalytic degradation of water organic pollutants, kinetic modeling and energy efficiency," Ind. Eng. Chem. Res., vol. 36, pp. 4705-4711, 1997.
[15] D. Chen and A. K. Ray, "Photocatalytic kinetics of phenol and its derivatives over UV irradiated $\mathrm{TiO}_{2}$," Appl. Catal. B Environ., vol. 23, pp. 143-157, 1999.

[16] R. W. Matthews, "Photooxidation of organic impurities in water using thin films of titanium dioxide," J. Phys. Chem., vol. 91, no. 25, pp. 3328-3333, 1987.

[17] A. H. Lim, K. B. Bautista, R. I. Sato, and M. L. P. Dalida, "Design and performance of an immobilized photocatalytic reactor for water treatment," B.S. thesis, Dept. Chem. Eng., Univ. of the Philippines Diliman, 2013.

[18] P. D. Ramoso and M. L. P. Dalida, "Design and optimization of an air-sparged, $\mathrm{TiO}_{2}$-immobilized tubular photocatalytic reactor for the degradation of methylene blue," M.S. thesis, Dept. Chem. Eng., Univ. of the Philippines Diliman, 2014.

[19] M. Uzunova-Bujnova, R. Todorovska, M. Milanova, R. Kralchevska, and D. Todorovsky, "On the spray-drying deposition of $\mathrm{TiO}_{2}$ photocatalytic films," Appl. Surf. Sci., vol. 256, no. 3, pp. 830-837, Nov. 2009.

[20] V. Bolis, C. Busco, M. Ciarletta, C. Distasi, J. Erriquez, I. Fenoglio, S. Livraghi, and S. Morel, "Hydrophilic/hydrophobic features of $\mathrm{TiO}_{2}$ nanoparticles as a function of crystal phase, surface area and coating, in relation to their potential toxicity in peripheral nervous system," $J$. Colloid Interface Sci., vol. 369, no. 1, pp. 28-39, Mar. 2012.

[21] K. Natarajan, T. S. Natarajan, H. C. Bajaj, and R. J. Tayade, "Photocatalytic reactor based on UV-LED/TiO 2 coated quartz tube for degradation of dyes," Chem. Eng. J., vol. 178, pp. 40-49, Dec. 2011.

[22] J. Zhao, H. Hidaka, A. Takamura, E. Pelizzetti, and N. Serpone, "Photodegradation of surfactants. 11. zeta-potential measurements in the photocatalytic oxidation of surfactants in aqueous $\mathrm{TiO}_{2}$ suspensions," Langmuir, vol. 9, pp. 1646-1650, 1993.

[23] H. Lachheb, E. Puzenat, A. Houas, M. Ksibi, E. Elaloui, C. Guillard, and J.-M. Herrmann, "Photocatalytic degradation of various types of dyes (Alizarin S, Crocein Orange G, Methyl Red, Congo Red, Methylene Blue) in water by UV-irradiated titania," Appl. Catal. B Environ., vol. 39, no. 1, pp. 75-90, Nov. 2002.

[24] S. Mozia, M. Toyoda, T. Tsumura, M. Inagaki, and A. W. Morawski, "Comparison of effectiveness of methylene blue decomposition using pristine and carbon-coated $\mathrm{TiO}_{2}$ in a photocatalytic membrane reactor,' Desalination, vol. 212, no. 1-3, pp. 141-151, Jun. 2007.

[25] B. I. Stefanov, N. V. Kaneva, G. L. Puma, and C. D. Dushkin, "Novel integrated reactor for evaluation of activity of supported photocatalytic thin films: Case of methylene blue degradation on $\mathrm{TiO}_{2}$ and nickel modified $\mathrm{TiO}_{2}$ under UV and visible light," Colloids Surfaces A Physicochem. Eng. Asp., vol. 382, no. 1-3, pp. 219-225, Jun. 2011.

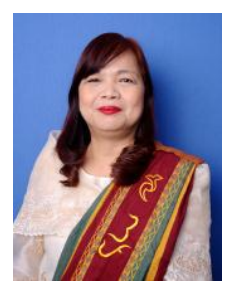

Maria Lourdes P. Dalida is an Associate Professor at the Department of Chemical Engineering, University of the Philippines Diliman, Quezon City, Philippines. She obtained her Ph.D. in Chemical Engineering at the University of the Philippines Diliman in 2005 and postdoctoral studies at the University of Houston in 2011.

She has over 20 years teaching experience in the said university and is currently the head of the Catalyst Research Laboratory and Bioprocess Engineering Laboratory of the department. Her research interests include photocatalysis, membrane separation processes, bioprocessing and wastewater treatment.

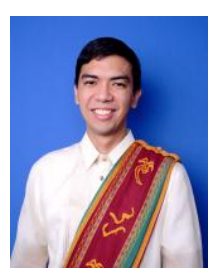

Patrick D. Ramoso is an Assistant Professor at the Department of Chemical Engineering, University of the Philippines Diliman, Quezon City, Philippines. He obtained his M.S. in Chemical Engineering at the University of the Philippines Diliman in 2014.

He was the Assistant Chair from 2015-2016 of the Department of Chemical Engineering. His research interest is photocatalysis and photocatalytic reaction engineering and reactor design for wastewater 